\title{
The Laser MicroJet (LMJ): a multi- solution technology for high quality micro-machining
}

Tuan Anh Mai, Bernold Richerzhagen, Paul C. Snowdon, David Wood, Paul G. Maropoulos

Tuan Anh Mai, Bernold Richerzhagen, Paul C. Snowdon, David Wood, Paul G. Maropoulos, "The Laser MicroJet (LMJ): a multi-solution technology for high quality micro-machining," Proc. SPIE 6459, Laser-based Micro- and Nanopackaging and Assembly, 64590P (20 March 2007); doi: $10.1117 / 12.701070$

EDIE Event: Lasers and Applications in Science and Engineering, 2007, San Jose, California, United States 


\title{
The Laser MicroJet ${ }^{\circledR}$ (LMJ) - A Multi-Solution Technology for High Quality Micro-Machining
}

\author{
Tuan Anh Mai ${ }^{* a}$, Bernold Richerzhagen ${ }^{\mathrm{a}}$ \\ Paul C. Snowdon ${ }^{\mathrm{b}}$, David Wood ${ }^{\mathrm{b}}$, Paul G. Maropoulos ${ }^{\mathrm{b}}$ \\ a'Synova S.A., Chemin de la Dent D’Oche 1, CH-1024 Ecublens, Switzerland \\ ${ }^{\mathrm{b}}$ School of Engineering, Durham University, South Road, Durham, DHI 3LE, UK
}

\begin{abstract}
The field of laser micromachining is highly diverse. There are many different types of lasers available in the market. Due to their differences in irradiating wavelength, output power and pulse characteristic they can be selected for different applications depending on material and feature size [1]. The main issues by using these lasers are heat damages, contamination and low ablation rates. This report examines on the application of the Laser MicroJet ${ }^{\circledR}$ (LMJ), a unique combination of a laser beam with a hair-thin water jet as a universal tool for micro-machining of MEMS substrates, as well as ferrous and non-ferrous materials. The materials include gallium arsenide (GaAs) \& silicon wafers, steel, tantalum and alumina ceramic. A Nd:YAG laser operating at $1064 \mathrm{~nm}$ (infra red) and frequency doubled $532 \mathrm{~nm}$ (green) were employed for the micro-machining of these materials.
\end{abstract}

Keywords: Laser MicroJet ${ }^{\circledR}$, water guided laser, MEMS, micro-machining

\section{INTRODUCTION}

In any production qualified process, the quality and the repeatability are unequivocally the paramount requirements. The ability to precisely control the machining results is pivotal in order to constantly reproduce a desired structure. In this paper, a series of experimental investigations were carried out to give a clear perspective into the potential capabilities of the Laser MicroJet ${ }^{\circledR}$ technology (LMJ) as a multi-solution process for the application areas covered here after.

1. Patterning of MEMS structures on silicon.

2. Cutting of a variety of other materials being used in the IC or MEMS industries, e.g. ceramics, ferrous and nonferrous metals.

3. Dicing of integrated circuits on a Gallium Arsenide (GaAs) wafer.

The greatest emphasis was placed on speed, cleanliness and repeatability of machining results. In comparison to deep reactive ion etching (DRIE-the major silicon patterning tool) the minimum feature size is considerably larger, however the LMJ provides significant advantages in other respects.

\section{THE LASER MICROJET TECHNOLOGY}

The water jet-guided laser technology combines in a unique manner the advantages of a high power pulsed laser with a hairthin jet of water jet to simultaneously cut and cool the work-piece [2]. The principle of this technology is shown in Fig. 1. The low-pressure water jet functions are three-fold. It acts not only as a liquid optical fiber for guiding the laser beam, but also simultaneously cools the work piece and removes the molten material and processing debris.

\footnotetext{
*mai@synova.ch, phone 4121694 3512, fax 41216943501
}

Laser-based Micro- and Nanopackaging and Assembly, edited by Wilhelm Pfleging, Yongfeng Lu, Kunihiko Washio, Friedrich G. Bachmann, Willem Hoving, Proc. of SPIE Vol. 6459, 64590P, (2007) · 0277-786X/07/\$18 · doi: $10.1117 / 12.701070$

Proc. of SPIE Vol. 6459 64590P-1 


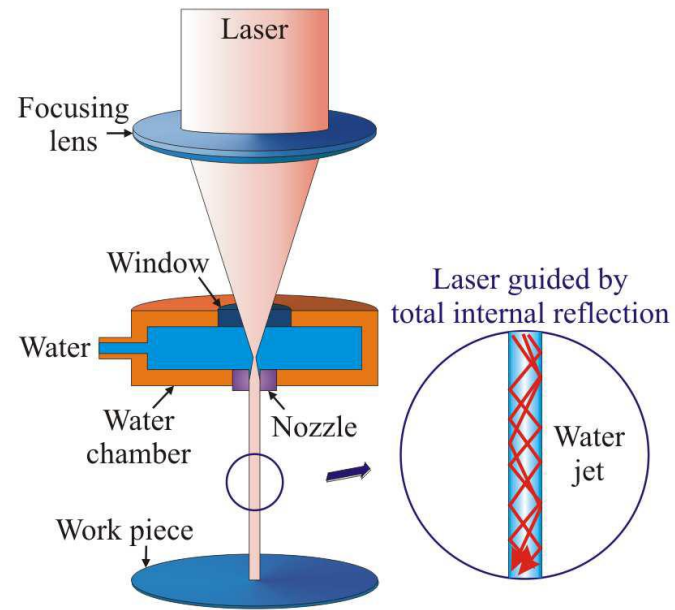

Fig. 1: Principle of the LMJ, coupling of a laser beam into a water jet

The laser beam is focused through a glass window on to the surface of the nozzle. The glass window and the nozzle form together a tiny pressurized water chamber [3]. The water jet exits the nozzle as a low pressurized jet, but having a long coherent length (a long and stable water jet of uniform diameter) and guides the laser down to the work piece via total internal reflection at the air/water interface. The diameter of the water nozzle, which ranges from $25 \mu \mathrm{m}-100 \mu \mathrm{m}$, directly controls the cutting diameter of the laser. The control of the geometries of both the chamber and nozzle are crucial for efficient coupling of the laser beam into the water jet. The long cylindrical water jet avoids the need of focus control. It carries the laser beam down to the bottom of the cutting kerf and allows us to machine materials with an extremely high width/depth aspect ration. The machining result is independent of the machining direction as problems related to the conventional dry laser process such as beam ellipticity and astigmatism no longer exist.

\section{MATERIALS FOR THE INVESTIGATIONS}

Table 1 lists the different materials used for this study. The silicon wafers were mounted on standard dicing frames. The frames contained an UV LaserTape ${ }^{\circledR}$ that was developed specifically for this process. The dicing frames were then mounted on a vacuum chuck.

Table 1: Materials for the investigations

\begin{tabular}{|c|l|}
\hline No. & Material description \\
\hline 1 & 2 mm Via hole (Silicon) \\
\hline 2 & Multiple 1 mm Via holes (Silicon) \\
\hline 3 & Spirals (Silicon) \\
\hline 4 & Pillars (Silicon) \\
\hline 5 & Steel foil \\
\hline 6 & Tantalum tube \\
\hline 7 & Ceramic chip packaging \\
\hline 8 & Gallium Arsenide wafer \\
\hline
\end{tabular}




\section{MICROMACHINING WITH LASER MICROJET}

\subsection{Surface structuring and via hole drilling on silicon wafers}

This particular structure (Fig. 2) was created by a spiral raster pattern scanning of the LMJ. The hole diameter was gradually reduced to zero, so that at the center a through via hole could be created. The machining time was 90 s for the $2 \mathrm{~mm}$ hole and $33 \mathrm{~s}$ for the $1 \mathrm{~mm}$ hole, shown in Figures 2 and 3 respectively.

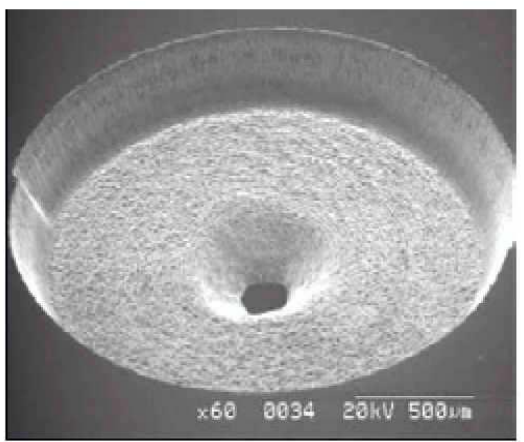

a)

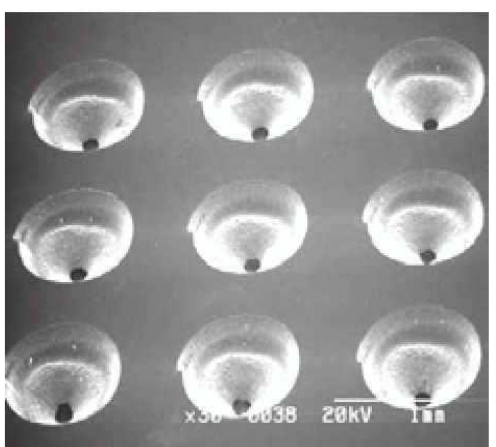

b)

Fig. 2: SEM image of a) a $2 \mathrm{~mm}$ diameter via hole and b) a $1 \mathrm{~mm}$ diameter via hole array

The results show an excellent repeatability of the process as the via holes are virtually identical to each other. Without any dedicated post-cleaning procedure, the obtained structured surface was clean and debris-free. A surface roughness $R_{a}$ of approximately $3 \mu \mathrm{m}$ was measured (Fig. 3a). Fig $3 \mathrm{~b}$ shows the back side of the silicon wafer.

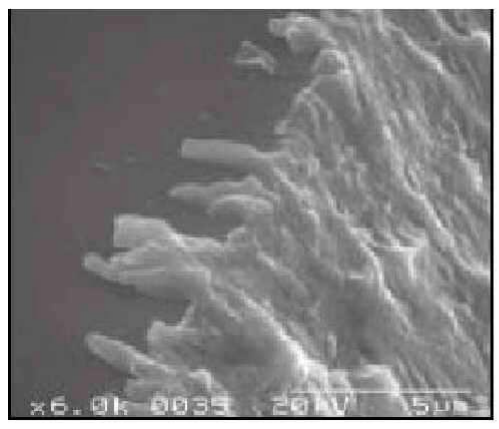

a)

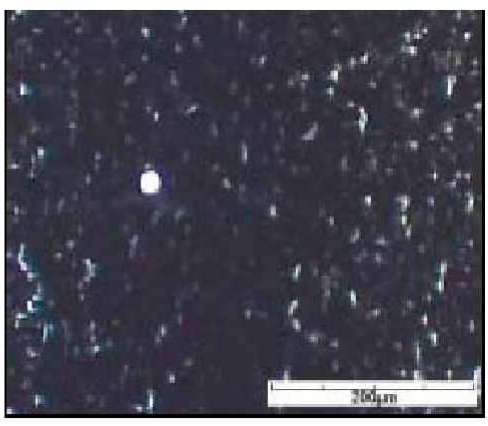

b)

Fig. 3: a) Rim of the $1 \mathrm{~mm}$ diameter via hole, b) Photograph of a via hole taken from backside

Fig. 4 depicts another machining process based on the similar cutting program but with a significantly larger pitch. The aim of this experiment was to produce the spiral structure with a thin wall and a high aspect ratio. It would help to examine the LMJ's ability to machine fine-pitch areas while leaving structures unscathed. 


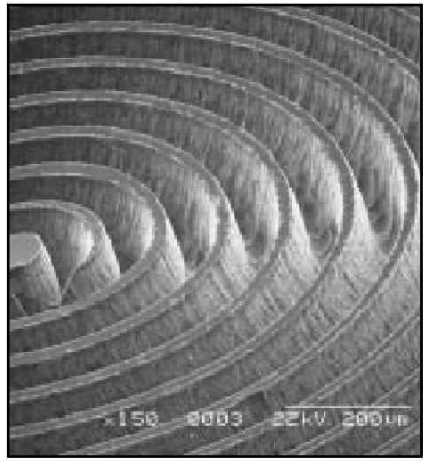

a)

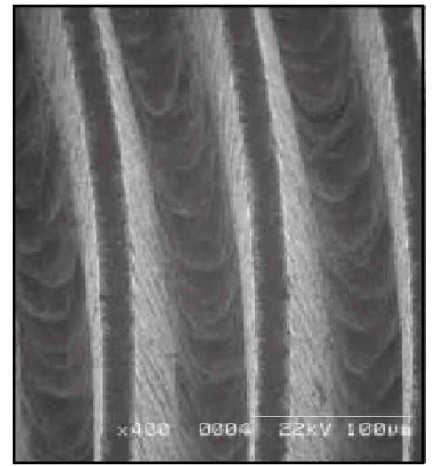

b)

Fig. 4: SEM images of the spiral illustrating sidewalls and bottom of the cut

After the cutting process was completed, the laser was switched off and the CNC program rerun using only the water jet, in order to clean out the channels of any remaining loose debris. The examination showed that the water jet had effectively cleaned the channel and that the walls of the spiral cuts were smooth and consistent in dimension.

In another experiment, "pillar"-like structures which have a pyramid shape were created by removing a large area of surface material in two perpendicular directions. The machined structures have a top surface area of approximately $10 \mu \mathrm{m} \times 10 \mu \mathrm{m}$ and are approximately $120 \mu \mathrm{m}$ deep. The consistency and repeatability of the machining process is evident in Fig. 5 .

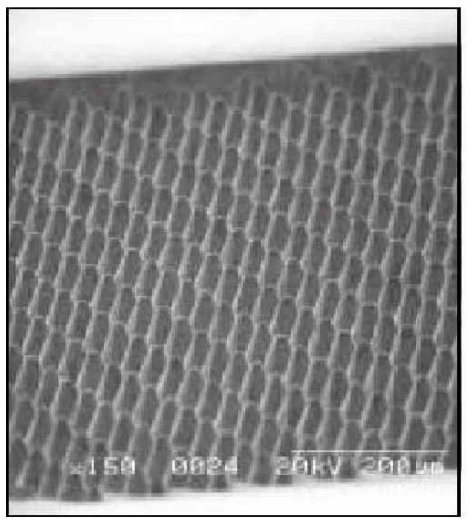

a)

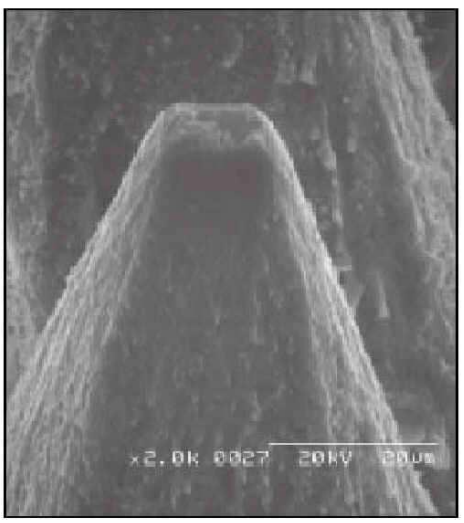

b)

Fig. 5: SEM images of a) a pillar array and b) the top part of a pillar

\subsection{Cutting of metals}

A sheet of steel foil of $100 \mu \mathrm{m}$ thickness was machined with a second harmonic Q-switched diode pumped solid state green laser. Fig. 6a shows the full pattern of the cut on an area of $16 \mathrm{~mm} \times 16 \mathrm{~mm}$. The length of each individual square hole is 500 $\mu \mathrm{m}$. Fig. $6 \mathrm{~b}$ shows the excellent quality of the cut edge with no color change and negligible heat damage. 


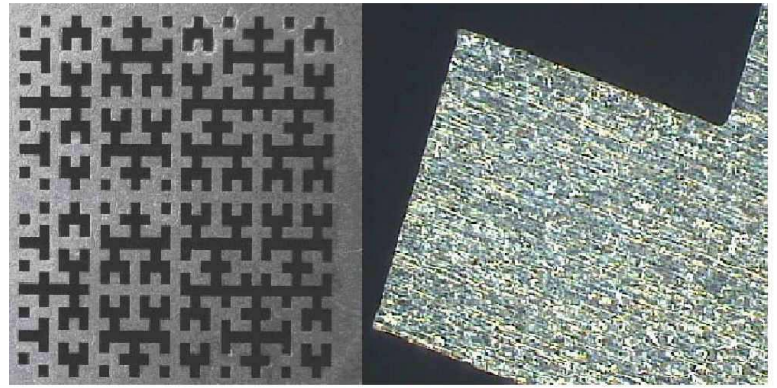

a)

b)

Fig. 6: Microscopic images of a) the machined Hilbert pattern and b) a rectangular section

The second harmonic $532 \mathrm{~nm}$ green laser was also used to machine a tantalum tube, which has an outer diameter of 3 mm and a wall thickness of $250 \mu \mathrm{m}$. The test comprised of machining $750 \mu \mathrm{m}$ diameter holes and producing $35 \mu \mathrm{m}$ wide slots (Fig. 7). The cutting process was carried out with a $40 \mu \mathrm{m}$ nozzle at a water jet pressure of 250 bar. The high quality of the obtained results demonstrates again the superiority and versatility of the LMJ process.

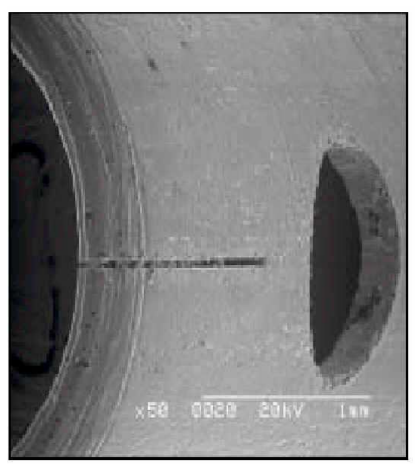

a)

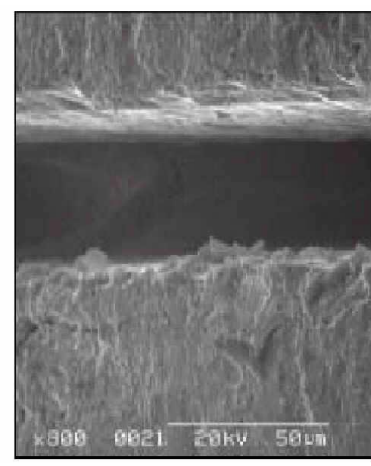

b)

Fig. 7: SEM images of a) the Tantalum tube showing the slot and a $0.75 \mathrm{~mm}$ hole and b) a $35 \mu \mathrm{m}$ wide slot

\subsection{Cutting of ceramics}

Fig. 8 depicts a $1 \mathrm{~mm}$ diameter hole machined through $1 \mathrm{~mm}$ thick Alumina ceramic. The alumina substrate is used for chip packaging and plated at one side with gold. After cutting, some of the plating peeled at the edge of the hole due to lack of adhesion. By adjusting water pressure and nozzle diameter, the delamination could be further minimized. 


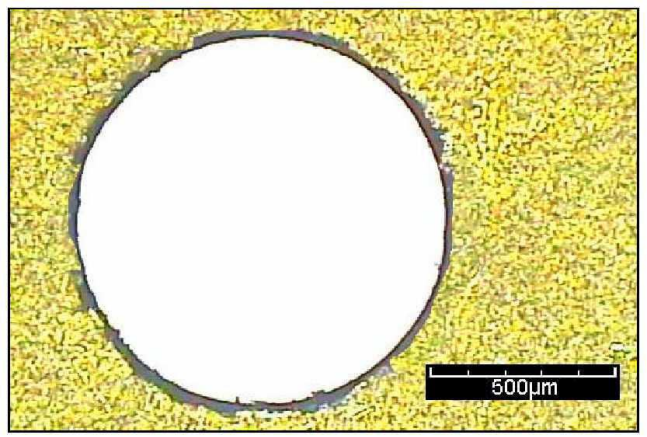

Fig. 8: Packaging ceramic with $1 \mathrm{~mm}$ hole

\subsection{Dicing of GaAs wafers}

The Laser MicroJet ${ }^{\circledR}$ technology has proved its capabilities in machining a wide range of materials for various industries. One of its main markets today is semiconductor processing and the technology has successfully been applied to silicon, low$\mathrm{k}$ wafers, InP, GaAs and SiC. Gallium arsenide $(\mathrm{GaAs})$ is a brittle, difficult-to-process material. It tends to chip and break when subject to mechanical constraints, such as those generated by abrasive sawing. To reduce cracks in mechanical methods, speed has to remain low; furthermore wide streets are needed. The diamond scribe-and-break method has low yield and suffers problems with backside metal layers and crystal orientation; it is not reliable enough and machine operator intervention is often needed. When dicing GaAs wafers with LMJ, the mechanical force caused by the jet is negligible (approximately $0.1 \mathrm{~N}$ ) $[4,5]$ and thus thin wafers (even below $50 \mu \mathrm{m}$ thickness) can be processed without breakage.

Another important aspect is the toxicity of GaAs ablation process. Safety issues are paramount during cutting since compound GaAs contains 51.8\%wt arsenic. By dicing with conventional dry lasers, contamination cannot be avoided and toxic gas is emitted while cutting. Tests performed with the Laser MicroJet ${ }^{\circledR}$ (see Table 2) shows that no arsine gas is detected in the air while cutting GaAs. This represents significant improvement compared to conventional laser cutting [6,7]. All arsenic is concentrated in the wastewater, which can be filtered out and disposed of in an environmentally controlled manner. Thus, Laser MicroJet ${ }^{\circledR}$ dicing of GaAs does not require any additional safety systems comparable to sawing.

Table 2: Arsenic concentration - results from GaAs trial run

\begin{tabular}{|l|c|}
\hline Arsine gas [ppm] & Not detected \\
\hline $\begin{array}{l}\text { Concentration of As in air } \\
{\left[\mu \mathrm{g} / \mathrm{m}^{3}\right]}\end{array}$ & $\begin{array}{c}130 \text { (in cutting chamber) } \\
\text { (outside machine) }\end{array}$ \\
\hline $\begin{array}{l}\text { Concentration of As in water } \\
{[\mu \mathrm{g} / \mathrm{L}]}\end{array}$ & 62700 \\
\hline $\begin{array}{l}\text { Wipe sample results } \\
{\left[\mu \mathrm{g} / \mathrm{cm}^{2}\right]}\end{array}$ & 30 (in cutting chamber) \\
\end{tabular}

An additional device has recently been developed to reduce particle contamination level even further. During cutting, a continuous water layer of controlled thickness covers the wafer, preventing the particles from attaching to the wafer surface. Removing the water layer containing suspended particles after cutting guarantees a clean wafer. The result is especially impressive compared to conventional laser cutting (Fig. 9). For this $100 \mu \mathrm{m}$ thick GaAs wafer, a Q-switched fiber Nd:YAG 
laser (wavelength $1070 \mathrm{~nm}$, average power $50 \mathrm{~W}$ ) has been coupled into a water jet of $25 \mu \mathrm{m}$ diameter. Processed wafers and dies are free of micro cracks, chipping and particles. Kerfs are constant and no contamination is visible.
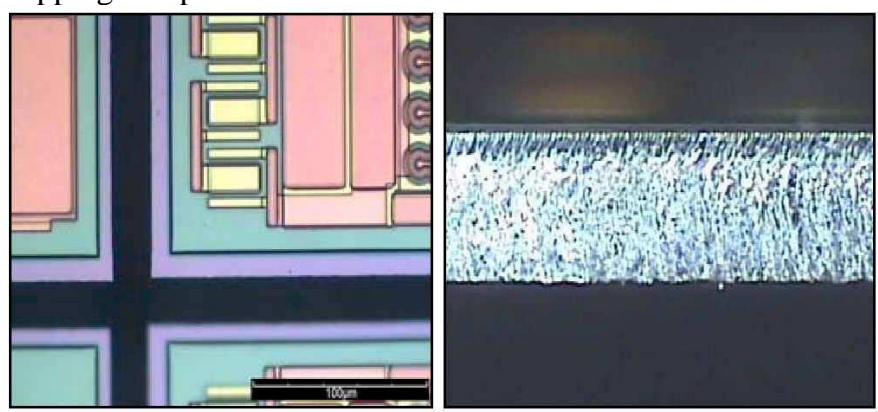

Fig. 9: a) A cross street dicing pattern (40mm/s dicing speed. $25 \mu \mathrm{m}$ kerf width); b) Wall surface

\section{CONCLUSION}

As noted at the beginning of this report, this series of experiments was designed to give an insight into the potential capabilities of the Laser MicroJet ${ }^{\circledR}$. The results presented in this paper show that the LMJ is undoubtedly an appropriate machining technology for various applications. The cuts are clean, reliable, accurate, and show negligible heat damage. In particular, the cutting of complicated shapes such as spirals and pillars provide excellent results, achieving consistent pattern transfer. The minimum feature size is limited when compared to DRIE, but if this is not an issue then the LMJ proves itself an attractive and multi-solution tool. It is a direct write process, fast, flexible and clean in both operation and in waste disposal [x]. The range of materials, which are suitable for the LMJ, is also great. The LMJ has proved to be an agile tool for the MEMS industry, and future trials will lead to additional new applications.

\section{REFERENCES}

1. M. Henry, et al., Laser Milling - a Practical Industrial Solution for Machining a Wide Variety of Materials, 5th International Symposium on laser Precision Microfabrication, 2004, Nara, Japan.

2. 0. Sibailly, et al., Laser micro-machining in microelectronic industry by water jet-guided laser, The International Society for Optical Engineering, 2004, Issue 5339, p. 258-264.

3. F.R. Wagner, et al., Water jet-guided laser versus saw dicing, The International Society for Optical Engineering, 2003. Issue 4977, p. 75-77

4. W. Kroninger, et al, Stress Release Increases Advantages of Laser MicroJet ${ }^{\circledR}$ Dicing, Semiconductor International, 2005, 28(4), p. sp4-sp8.

5. B. Richerzhagen, D. Perrottet, R. Housh, Enhanced fracture strength of thin wafers and chips due to Laser MicroJet ${ }^{\circledR}$ technology, Thin Semiconductor Devices - Manufacturing and Applications, Munich, Germany, Dec.2000

6. D. Perrottet, J.M. Buchilly, B. Richerzhagen, Water jet-guided laser achieves highest die fracture strength, Future Fab, Issue 18, May 2005, page $157-159$

7. D. Perrottet, A. Spiegel, S. Amorosi, B. Richerzhagen, GaAs-wafer dicing using the water jet guided laser, CS Mantech 2005, New Orleans, USA, April 2005 